\title{
Coalitions for a common purpose: managing relationships in experiments
}

\author{
Heather Strang
}

Published online: 8 May 2012

(C) Springer Science+Business Media B.V. 2012

\begin{abstract}
Objectives To discuss the character of relationships between operational and research staff and the necessary conditions for successful experiments.

Methods A review of research and experience in the conduct of experiments, especially randomized controlled trials, examining the foundations for success, issues in maintaining cooperation with operational staff, implementation and leadership issues.

Results The fundamental issue in successful experiments is the relationship between the operational and research entities, which most often resemble a coalition of temporary common interests rather than a partnership between parties with long-term common goals. Conclusion Experiments require close cooperation between the parties because of the need for maintenance and monitoring. Researchers who use field trials have solved many of the common problems faced by those embarking on experiments and those who do so will be rewarded by the quality of their findings. Relationships which may be characterised as temporary coalitions for a common purpose may, under the right conditions, ultimately mature into true research partnerships.
\end{abstract}

Keywords Managing experiments · Research relationships · Evaluation research · Implementation issues $\cdot$ Coalitions $\cdot$ Field manager

\section{Introduction}

Relationships between researchers and operational partners in a randomized controlled experiment (RCT) can sometimes be characterised as symbiotic, such as that

\footnotetext{
H. Strang $(\square)$

Institute of Criminology, University of Cambridge, Sidgwick Avenue, Cambridge, Cambs CB3 9DA, UK

e-mail: hs404@cam.ac.uk
}

\section{H. Strang}

Australian National University, Canberra, Australia 
between oxpeckers and rhinoceroses. This tends to be the case when there is a high degree of common purpose in a jointly undertaken enterprise, and a high level of understanding of each others' roles and responsibilities. Sometimes, the relationship may look more like a complicated and delicate dance: seamless and straightforward on the surface but encompassing many stressors and points of tension. On occasion, it can descend into a relationship resembling a dysfunctional marriage with low trust, low empathy and a good deal of resentment on both sides.

Across the 12 or so field trials the author has managed, relationships of all these kinds have manifested themselves, sometimes within a single experiment. The main lesson learned from these experiences has been that high quality experimental research depends immeasurably on the quality of the relationship between those who have the data and those who need it for the purpose of answering important research questions. Success depends on establishing and maintaining workable relations between the parties, in spite of the obstacles that may lie in the path.

RCTs have often been advocated as the preferable method for evaluating public policy (see, e.g., Farrington et al 1986; Weisburd 2000), but they have been used relatively infrequently compared with nonexperimental methods. Weisburd (2000) suggests a range of ethical, political and practical barriers facing experimentalists - or 'trialists', as they are known in the health sector - that will be discussed in this paper. But first, I will explore some preliminary considerations for successful experiments, including what can be broadly called the cultural environment in which experimentalists must work, and the likely causes for reluctance to undertake experiments in criminology. I then discuss challenges often encountered in conducting RCTs, both in setting them up and especially in implementing them, and experiences of the author in addressing these. Finally, I will propose that the fundamental issue to be addressed if experiments are to succeed is the relationship between the operational and research parties, which I characterise not as a partnership, for reasons I will explain, but as a coalition of temporary interests that require a particular kind of leadership. I conclude that, unlike research employing purely observational methods, randomized experiments entirely depend for their success in achieving an unbiased comparison between experimental and control conditions upon the quality and strength of the relationship forged between the partners, and it is this topic that is the focus of the paper.

\section{Preliminary considerations}

\section{Awareness of the cultural environment}

People engaged in empirical research have inquiring minds and have usually been trained to be sceptical and objective. They do not mind uncertainty: it is their default position. They are not strongly attached to one view or another and do not spend their days delivering programs in which emotional investment can be high. Their operational counterparts, by contrast, have a different perspective. They are usually practical people who often employ principles and practices in performing their jobs that they have inherited from their mentors and share with their colleagues. These are not always based on empirical evidence and sometimes are the result of experience and accepted wisdom. Uncertainty about their daily responsibilities and actions may make them uncomfortable. This reality must be grasped by the entire research team at 
the earliest possible moment because it will usually be the unspoken factor in every interaction between the two parties.

\section{Particular issues with experiments}

It is certainly true that all high quality experimental research, whether RCTs or quasiexperimental studies, experience challenges. The very reasons for which experiments demand good relations between the research and operational teams are the reasons that can present particular difficulties for operational people. In common with other rigorous research designs that yield high quality results, they are complicated to set up, they often require extra work and they go on for a long time, often longer than planned. They may be seen as threatening because of the possibility that the program under examination will be found wanting, when the deliverers of the program have a high level of commitment to its value. Experiments are expensive (though no more expensive than equivocal or bad evidence that lead to bad decisions) and employ funds that people committed to the program feel would be better spent on the program itself. In addition, and correctly, they may feel they are being observed and scrutinised by people with very different values from their own. Absent deliberate efforts to address these realities, operational people are likely to feel at best disrespected and at worst oppositional and hostile to the research team who depend entirely upon their cooperation for success.

RCTs experience all these challenges and some additional ones too. Notably, research using this design requires adherence to proper randomization procedures. While this responsibility should always remain with the research team rather than the operational team, the way in which it is worked out will always require cooperation and consultation between all parties. Implicit in randomization is another concern for the operational team: when practitioners feel the program is a valuable one, they may have genuine concerns about withholding it from the control group. This may be one of the most difficult issues to deal with in setting up the experiment and will be addressed shortly. The point to be made, nonetheless, is that, while so many of these problems are also faced in non-experimental and quasi-experimental research, the quality of the findings that RCTs deliver are such that any additional effort is handsomely rewarded.

\section{Establishing foundations}

\section{Intellectual foundations}

In deciding what questions to ask, the experimentalist is often interested in those of greatest theoretical importance, rather than in answering a rather arid 'what works best' question. But a technical understanding of which questions are practically testable and which are most useful, especially in regard to costbenefit, can be derived only in close collaboration with the operational party. If the motivation for the experiment comes from the operational side, it often makes most sense for the researchers to be involved in shaping the intervention itself. Working closely with those providing cases and delivering the intervention will ensure that all the data elements needed to compare outcomes are captured in the course of the study rather than pieced together retrospectively. 
In any case, it is never too soon for the parties to start discussing what research questions are to be answered.

Regardless of whether the original motivation for the study comes from the research side or the operational side, many experimentalists have recommended working collaboratively with operational staff at all phases of design as well as implementation (see, e.g., Garner and Visher 1988; Petersilia 1989; Feder et al. 2000). All emphasise the need for an open, collaborative process where both parties are responsive to issues the other sees as important. Feder (2011), for instance, has made explicit recommendations for running a field experiment in a community setting, while Braga and Hinkle (2010) propose a set of observations on how researchers should interact with criminal justice practitioners in collaborative research, regardless of the research design. Particular advice is offered on collaborations between researchers and police by Greene (2010), who reflects on ways in which learning from both success and failure can improve relationships, and by Weisburd (2005), who draws eight specific lessons for successfully developing and implementing RCTs. All these observers agree that, in general, cooperation through the long days of data collection is more likely if everyone understands what questions will be asked and agrees on the means for answering them. This is especially true if operational staff see that the outcomes are relevant to their work, notwithstanding Feder's (2000) observation that "[A]gencies do not always give first priority to obtaining information to make better decisions" (p. 391).

We must also remember that enthusiasm by operational people for the project may sometimes be confused with enthusiasm for the intervention to be tested. This may be especially likely if the intervention is a controversial one without full support within the agency, as we found with our drinking-and-driving restorative justice experiment in Canberra, one of four studies making up the Reintegrative Shaming Experiments (RISE) (see Strang (2002) and http://www.aic.gov.au/en/criminal_justice_system/ rjustice/rise/ for reports on all aspects of results from these experiments). A minority of police officers loyally referred cases to us over a two-year period, despite being mocked by their colleagues for supporting a 'soft' option compared with court. But these officers often told us that they did so because they 'believed' in restorative justice. Explaining the difference between seeking a clear finding about effectiveness and showing that a program 'works' is not easy when the audience does not share a research mindset which values the former more than the latter. It is the relentless job of the entire research team to try to make this distinction clear and to avoid the dismay that can follow a disappointing result. It was a difficult job indeed at the end of that particular experiment to tell those officers that restorative justice had not 'worked'; they were unlikely to sign up for another research enterprise in the future.

\section{Social foundations}

The establishment of a set of human relationships and social networks between the research team and the leadership of the agency and the operational staff involved in program delivery is the first step in setting up an experiment. This usually begins with a high-level approach from the Principal Investigator to the agency (or occasionally the reverse). Criminal justice agencies tend to conform closely to Weber's vision of bureaucratic authority whereby "the principles of office hierarchy and of levels of 
graded authority mean a firmly ordered system of super- and subordination in which there is a supervision of the lower offices by the higher ones" [Gerth and Mills 1948 (1991): 197]. This does not mean staff in these agencies will mindlessly conform to orders from their superiors, however, and they can be quite inventive about avoiding compliance if they do not wish to cooperate. The autonomy and discretionary powers of police officers, for example, means that there is no sense in relying on the command and control aspects of policing; police officers involved in experiments need to be convinced in the same way as any other operational party of the value of cooperation. Nevertheless, in policing as elsewhere it is necessary to start at the top.

\section{Formal foundations}

Formal agreements need to be negotiated with the leadership of the agency, whose unequivocal and clearly expressed support for the experiment is essential. This often takes the form of a Memorandum of Understanding (MOU), setting out the formal contractual obligations entered into by each party. These include matters such as access to and ownership of the data, privacy and confidentiality issues, conditions under which police data will be held by the research team, estimated length of the study and anything else of mutual concern. Even though in a successful experiment the MOU may never be referred to, it can become vital in the event of trouble. But relying on it is a poor substitute for personal backing of the project by the leadership, as we found in our RISE experiments in Canberra. We began RISE at the beginning of what turned out to be a turbulent time in police leadership over the five years we took to complete data collection, with a rapid turnover of chiefs each with a decidedly different view of our work. The sustaining factor for the continuing cooperation of the agency was their legal obligation to continue, but caseflow suffered greatly during periods of sullen relations.

Beyond the 'legal' status of the MOU, experimentalists may consider designing an experimental protocol that sets out with some precision the way the experiment will be conducted and identifies the data that are needed. The discipline of this document, which is agreed by both the research and operational parties before the experiment begins, can be an important safety net for the research team in avoiding problems as the experiment gets underway. A model for criminological research developed at the University of Cambridge Institute of Criminology (http://www.crim.cam.ac.uk/research/experiments/), lays out what is needed for the experiment to succeed. These elements include eligibility criteria, the unit of analysis, the pipeline of cases, random assignment procedures, definition of experimental and control conditions, how the intervention will be managed and measured, how outcomes will be measured and how the results will be analysed and disseminated.

Beyond the protocol, there must be a way of avoiding the problems identified by Weisburd et al. (1993) in experiments that fail to report fundamental information such as design characteristics and subject attrition (even in high-quality peer-reviewed journals). The Cochrane Collaboration's CONSORT statement (Consolidated Standards on Reporting of Trials), (http:/www.consort-statement.org/consort-statement), published in 1996, offers a model for consistent reporting of trial design, analysis and interpretation. The 25 -item checklist includes items about the objectives of the study, sample size, recruitment arrangements and attrition at every stage. It is readily 
adaptable to criminological experiments and adhering to it allows for much greater transparency in interpreting results.

\section{Maintaining cooperation}

Getting permission to begin is one thing; sustaining active cooperation through the implementation phase is the challenge. Top-down support from the chief executive officer of the agency is necessary but not sufficient; even strong support from the top is not enough to ensure the level of cooperation needed at all levels of an agency for a successful experiment. Agreement at the top can dilute as it descends the chain of command. As Ross and Blumenthal (1975: 154) concluded from their study, which failed in spite of high-level cooperation from judges and police: "...the weight of promises by top-level representatives of bureaucracies is considerably attenuated at the bottom of the organizational structure, absent strong control procedures, and...the day-to-day pressures of bureaucratic 'clients'... are more weighty than those which researchers can bring to bear."

Experiments demand adherence to the agreed protocol, which may require the suspension of usual practices for the life of the experiment. Problems can arise when it is not possible or not appropriate for the researchers to be present at all material times to remind operational staff of the need to stick to the agreement. This was certainly the case in RISE. Because of the kinds of cases we were looking for, driving while over the proscribed alcohol limit, property and violent crimes, most eligible offences occurred through the night across the city of Canberra and it was not often feasible for research staff to be around when police responded to these offences. Our pipeline analysis of all ostensibly eligible cases indicated that we received into our experiments no more than 12 percent of them ${ }^{1}$ - one of the main reasons that RISE took five long years to reach the minimum number of cases required for viable experiments in property and violent offenses committed by young people. ${ }^{2}$ Of course, experiments do not have to take as long as this to complete. For example, data collection in a study currently underway in collaboration between Cambridge University and a large British police force was completed in less than six months mainly because of the high level of commitment of the operational partners. But it pays to be conscious of the case flow problems discussed below before estimating how long an experiment is likely to take.

All operational staff in the agency whose responsibilities touch on the experiment need to understand the nature and purpose of the study. But those delivering the intervention are absolutely vital to the enterprise. Ideally, those closest to the research team should be volunteers with a genuine interest in the results of an unbiased study, but that is rarely the case. The reality is that they must be consulted and communicated with throughout the study, often on a daily basis, so that the research team can be sure that they all understand the rationale for the research design and why the parties are working

\footnotetext{
${ }^{1}$ Eligible offence categories in RISE were agreed between the research and operational parties but no police officer was compelled to refer any particular case to the experiments because of the additional eligibility question, namely that the police officer believed the offence was serious enough that it would normally be dealt with in court but not so serious that it must go to court. As we discovered, police officers were rather infrequently willing to admit to this level of indecisiveness about how to proceed.

${ }^{2}$ Sufficient statistical power to detect effects is partly a function of sample size.
} 
together. Researchers need both to engender enthusiasm for the enterprise, especially for reasons of caseflow, and to safeguard against threats to the integrity of the experiment. Without this kind of bottom-up cooperation the experiment may be doomed, so numerous are the ways in which it can be undermined by poor implementation.

\section{Implementation issues - what can possibly go wrong?}

The implementation stage can be the most demanding faced by experimenters because of the plethora of unexpected issues that arise as soon as the demands of the research design intersect with operational realities. As Berk (2005: 431) observes: "Randomized experiments rest on more complicated, subtle and fragile foundations than some researchers appreciate. Proper implementation of randomized experiments is demanding. Textbook requirements are rarely met." Ingenuity and problem-solving skills, as well as good relations at every level, are required to navigate these issues.

Getting the cases

One of the few certainties about conducting RCTs is that there are always fewer eligible cases than are anticipated, based on apparently reliable historical information. This is such a common problem that Boruch (1997: 71) quotes an anonymous source as saying "As soon as the contract is signed, or the grant is awarded, the size of the target group available for the experiment drops in half."

Boruch's suggested solution to this problem is the use of pipeline studies before the start of the experiment. This is a good idea in theory, and also in practice sometimes (Sherman 1992), though the sheer volume of eligible, ostensibly eligible or downright ineligible cases that can come down the pipe, as they did in RISE, can almost overwhelm the research team. It does not in any case allow for the idiosyncratic decision-making at the 'coal face' when operational partners have the undeniable right to cast aside cases that are perfectly suitable in the eyes of the research staff; undeniable because if they are ever going to reject a case it is far better that they do so before random assignment than after. Nevertheless, the exercise is critical for establishing the limits of the study's external validity and for understanding the processes of systematic bias that may be at work in the data collection process.

But we can only work with the cases we get referred into the experiment. It is here that the skill of the research team really comes into play because maintaining caseflow is every bit as challenging as getting the experiment off the ground in the first place. Electronic checking can be used to identify where cases are being lost, but it is an entirely human process that is needed to fix the problem. It is a fact of life that, unless the operational people whom we want to refer the cases feel invested in the study, case flow will diminish as time passes. They will lose interest, they will prioritise their own concerns, they will forget their promises and they will be replaced by new people who never had any interest in the study.

All these problems must be addressed by the research team every day. Whatever it takes to keep the experiment in the minds of those who can refer the cases must be used. In the experiments conducted by the author and colleagues in Northumbria, UK (see Shapland et al. 2004, 2006, 2007, 2008 for all aspects of these UK restorative 
justice experiments), our resourceful research manager identified the magistrates' clerks as the key people to persuade. She established a routine of arriving with cakes and buns for them mid-afternoon at least once a week, and the pay-off was a viable experiment with a fascinating result. Oddly, we were forbidden by senior officers in Canberra from 'bribing' station officers with cake, but they did allow us to take latenight ride-alongs with patrol officers to whom we endlessly explained the purpose of the research and the gratitude we would feel for every case referred to us. In London, where our quarry was Crown Court judges who needed to understand about our experiments, one of the Presiding Judges urged us to 'send in the blondes', knowing how persuasive our research team was.

Caseflow will be even more seriously affected if there are pockets of outright resistance to experiments within the operational agencies. This problem can be especially nettlesome when the aim of the RCT is to evaluate a programme that agency staff are emotionally invested in-indeed their jobs may also depend on it (see, e.g., Feder 2000). But it can also occur when operational staff simply prefer to do things the usual way or when they believe the programme is a waste of their time. This was a real problem in RISE, where many police saw restorative justice, the intervention being tested, as a 'slap on the wrist' and an affront to their more punitive leanings. We found in our experiments in the United Kingdom that police are not the only ones with 'cultural' perspectives that can affect experiments: social workers, probation officers, mediators and lawyers all have their particular world view in matters of criminal justice. We need to acknowledge in any case that it is generally easier to do things the 'old' way and for operational staff to do things differently may be inconvenient and time-consuming. Research staff must recognise this reality.

In addition, changing circumstances within the organisation can have profound effects on levels of cooperation. In RISE, we were aware of rumbling hostility to our research from the outset, though it was barely audible while the Canberra Police Chief who had enthusiastically embraced the idea of our RCT was in place. But his demise at the end of our first year of data collection was the signal for a battalion of opponents to gain the ascendancy. As mentioned earlier, this was the moment that we realised the value of our 16-page MOU was not to ensure cooperation but to prevent complete breakdown of the relationship. The five years of data collection for this experiment was a roller-coaster from this point of view, with four chiefs during that period, each of them with a different view about RISE. RISE was probably particularly unlucky with this experience-turnover at the top has never occurred at this pace in other experiments with which the author has been involved-but it pays to be aware of the consequences of a potentially unstable operational environment.

\section{Eligibility screening}

The research team must sustain eternal vigilance about the cases allowed into the experiment. Even some academic researchers may not be aware that ineligible cases cannot be deleted from an experiment after random assignment without causing the selection bias it is designed to control, because it affects the equivalence of the groups. This is an especially problematic issue to explain to non-research people because it is not obvious that letting in cases that do not fit the agreed criteria can so seriously undermine the whole study. 
It is at this point that every experimenter wishes that the study called for 'batch' random assignment, where many or all of the cases are assigned at once. With 'trickle flow' cases may be referred to the 'random assigner' at all hours of the day and night. RISE rostered on staff 24 hours a day seven days a week for five years to achieve the number of cases needed for valid results. It is in the nature of experimenting with the police that eligible cases are likely to be referred on the night shift when officers are wide awake but research staff are not. When the police called, researchers were required to ask a list of ten or so eligibility questions which provided a safeguard against accepting ineligible cases. This also ensured that they were awake enough to carry out the random assignment process by opening the correct envelope in the appropriate series (the somewhat antiquated assignment method used) and correctly identifying what should happen to the case.

\section{Pilot testing}

Boruch has observed (1997: 166) that "[N]o design for a randomized field test can anticipate all the issues or obstacles that may emerge in its execution." While this is self-evidently true, disaster can be avoided by making room for a 'run-in' period or 'Phase 1' as it is called in medical clinical trials, where cases are referred into the study and the intervention administered but no random assignment takes place. Experimenters are sometimes reluctant to make time for this stage and worry as well that using up valuable cases pre-random assignment will result in a deficit for the experiment. But actually putting the operational and research teams through their paces and complying with all facets of the research design short of random assignment can reveal weaknesses, especially around adequate caseflow and eligibility questions that would not otherwise be apparent until the experiment is ' a ship at sea', when all fixes are difficult to make.

\section{Managing random assignment}

Weisburd (2000: 189) has said "the problem of maintaining the integrity of experimental treatments is the most difficult task for researchers once randomization has been successfully implemented. Although treatment integrity is an issue in any research design, it is particularly important in randomized studies because there is little option for taking into account treatment failures once the experiment has begun."

The integrity of the entire experiment is only as good as the integrity of the randomization process, and it is for this reason that the process of randomly assigning cases must always remain in the hands of the research team, no matter how high the level of trust between the parties. It is always necessary to be vigilant about randomization being deliberately violated by those who genuinely believe it would be wrong to deny a particular case the experimental intervention, as occurred in the famous Lanarkshire milk experiment ('Student' 1931). However, misassignment, where cases assigned to the experimental condition are treated in the control condition and vice versa, usually occurs innocently. It happened a handful of times in 1,400 random assignments in RISE, almost always because of an error on the part of a sleepy 'random assigner' rather than deliberately by the referring officer. 
This low rate of misassignment was largely due to the original agreement that specified officers were not compelled to refer all ostensibly eligible cases but only those they were comfortable could be dealt with by either the experimental or control condition. Ross and Blumenthal (1975: 155) concluded from what they saw as their own errors that "Where client pressure to deviate from research prescriptions is likely to be intense, this pressure should be allowed to have its effect before the decision affecting experimental validity is made... Only if [the judge] felt that any of the treatments would have been appropriate could he have been directed to open a sealed envelope to determine the experimental prescription. Of course, this procedure would have compromised the external validity of the study, but internal validity would have been maintained. The results would have been interpretable for the group meeting the experimental criteria."

\section{Attrition from the study}

Losing cases post-random assignment is the nightmare that haunts all experiments. It means reduced statistical power and also the possibility of serious bias if the loss is differential between the experimental and control groups. It has many causes and the author has experienced many of them, including participants changing their minds about being in the study, participants absconding or otherwise being impossible to contact between assignment and intervention delivery, files being lost and no intervention given, participants reoffending post-random assignment and their case being withdrawn from the study. Some of these circumstances are foreseeable, but most can be minimised only by the research team impressing on operational people that to lose cases this way has the potential to completely undermine the value of the research findings.

\section{Consistency of delivery of the experimental condition}

For some experiments, the distinction between the experimental and control conditions is straightforward and clear, for example early release from custody compared with full term. But for others involving complex and protracted elements, such as restorative justice, treatment within the experimental arm may not be so easily standardised. It is best addressed by emphasis on training, both for the operational parties delivering the intervention and for the research team who should audit compliance through regular observations. Everyone needs to be very aware of the difficulties in drawing conclusions from heterogeneous treatment delivery. An auditing regime whereby a portion of the program is systematically monitored can be very helpful. RISE research staff attended virtually all restorative justice encounters in the experiment (as well as almost all court/control disposals) and found that the police officers delivering the intervention were always pleased to have informal feedback on the meeting, providing an opportunity for research staff to point out any inconsistencies. ${ }^{3}$

\footnotetext{
${ }^{3}$ Notwithstanding the fact that in RISE many restorative justice facilitators asked for feedback, the research team's inability to truly influence practice in our formal role of program evaluator led us to bid for a role in the Home Office-funded UK experiments (Shapland et al. 2004) not as evaluators but as program developers. This allowed us legitimately to have much more engagement with the practitioners in the way the treatment was delivered.
} 
Monitoring and measuring program delivery

Researchers sometimes assume that once a condition is assigned it will be delivered according to the agreements made before the experiment began. Consistency of delivery of the experimental intervention can at least be estimated through proper investment in systematic observation and interviews, even if it cannot be guaranteed, but the only compliance leverage the researchers usually have to hand is the social capital they have built up with their operational counterparts to persuade them to adhere to the intervention's essential features. This was especially problematic in RISE: in the mid-1990s when these experiments were conducted there was little accord about what constituted the sine qua non of a restorative justice conference. Values and processes were discussed but not necessarily agreed among practitioners (Strang and Braithwaite 2001), even though there was broad agreement that facilitators should be impartial, should encourage all parties to speak, should not be domineering or over-directive or impose their own points of view. While many facilitators adhered closely to these principles, others did not (Strang 2002): the research team were able to observe many breaches that potentially undermined the integrity of the test and to warn the agency about these problems.

Monitoring at every stage is important. In our London robbery and burglary restorative justice experiments (Shapland et al. 2008), a routine review of sentencing decisions for our participants revealed a worrying trend. In these experiments, eligible offenders were randomly assigned either to the usual Crown Court process alone or to a restorative justice conference in addition to the usual court process. For those in the experimental condition, the restorative justice event was held before sentence and judges were given a brief statement about the specific outcome agreement reached between the victim and the offender. To our alarm, we found that when we analysed the sentences of the experimental and control cases, even controlling for prior history and offence seriousness, our experimental cases were on average being dealt with more harshly. Our research team spoke to a number of judges and concluded that some of them felt that offenders who had taken part in restorative justice were exploiting the good will of their victims and they did not believe that their expressions of remorse were genuine. As a result, we withdrew the brief outcome agreement previously supplied to the judges and instead began preparing lengthy summaries of what our researcher team observed. These included details of the offender's demeanour at different stages of the meeting with the victim and a careful description of the emotions expressed and experienced by all parties as the meeting progressed. In this way, judges could better decide for themselves about the likely sincerity of the offenders and the level of satisfaction expressed by the victim. Almost immediately, our judges began sentencing the two groups much more equivalently.

\section{Managing the relationship: leadership issues}

I suggested at the outset that the fundamental issue in successful experiments is the relationship between the operational and research entities. This is commonly referred to as a 'partnership', but I propose that this characterisation invites misunderstanding. A partnership traditionally exists between parties with much in common who wish to 
pursue long-term common interests. But usually in experiments, the parties have divergent interests and divergent goals and their perspectives and roles are often poles apart. ${ }^{4}$ I suggest therefore that a more useful and less misleading term to use about these relationships is that of coalition, defined by Rubin (1997: 132) as "an alliance, usually limited in time and purpose, between organisations with differing agendas, working together for a common ...goal... Coalitions allow different interests to work together and at the same time to maintain their separate policy agendas." Rubin further observed that coalitions are alliances between organisations, not individuals, and that each brings with it its own particular agenda, priorities and decision-making process, all of which need to be accommodated in the agreement between the parties in a process of give and take.

Perhaps a better definition for our purpose is the one proposed by Mizrahi and Morrison (1993) which relates specifically to social change coalitions: "..an organization of organizations who share a common goal; [is] time-limited and characterized by dynamic tensions" (p. 14). These tensions relate to issues such as leadership, decision-making arrangements, goals, different professional perspectives and different levels of commitment. The question of commitment to the project was a lively one in RISE: for the police, there was little cost aside from the slight inconvenience of the RISE procedures when they felt like giving a case to the research team, while for the researchers, scarce funding was burning up every day that data collection was underway. The researchers lacked any levers to compensate for this mismatch in commitment and to expedite caseflow beyond persuasion, persistence and enthusiasm to the extent that it had a contagion effect.

In relationships of such complexity, Mizrahi and Morrison (1993: 15) assert that "coalition harmony cannot be sustained by appeals to rationality, facts, justice and democratic process alone" and must be resolved through processes of negotiation so that agreements emerge from mutual consent, because the objective is not unanimity but a working relationship. Furthermore, they observe that coalitions formed for a specific purpose such as those we are discussing focus on providing the minimum structure for them to function effectively and to sustain the arrangement for a specific shared purpose, and avoid process issues that take up valuable time.

This unavoidably unstable entity, short-term as its objectives may be, must get involved in some important joint strategic decision-making if it is to accomplish its objectives. This is likely to be a messy and disordered process because the decisions that emerge can upset established ways of doing business and threaten the identities of those affected. Hutt et al (1995) observed three major difficulties were common in these circumstances: 'turf' battles, interpretative misunderstandings and communication difficulties. Each of these is likely to be faced as an experiment gets underway.

Turf, which includes particular tasks or particular expertise, usually defines the identity of the people working in the area, so that when, for example, a police officer is asked to suspend usual practices for dealing with a criminal matter and instead

\footnotetext{
${ }^{4}$ I should record an important exception here. Cambridge University is presently pursuing a series of randomized experiments in collaboration with several British police forces. One of these has established a special unit to provide the operational expertise for several studies of specific interest to the police themselves under the general advice of the staff of the Jerry Lee Centre for Experimental Criminology. This bodes well for a breakdown in the barriers that so often separate research and operational personnel.
} 
comply with a random assignment sequence, we can expect trouble without adequate consultation.

Interpretive misunderstandings arise when those engaged in the enterprise have very different perspectives about the goals to be achieved. For example, police chiefs may be purely focused on the short-term crime reduction effects of the innovation to be tested, while researchers may be equally interested in its effects in the longer term, its specific or general deterrence properties, its effects on different kinds or offenders and offences. Agreement via an MOU can help define the collective objectives and protect against the premature withdrawal of one or other party.

Communication barriers can arise because of the tendency of groups to develop shared language and meanings that may be specific to the group. For example, in RISE, researchers felt they had solved an important problem when they decided among themselves that case eligibility would hinge on police officers using their discretion to decide that a case was serious enough that it could be dealt with by sending the case to court in the usual way but that it was not so serious that it must be sent to court. This turned out to be a huge problem: police are trained specifically not to be indecisive but always to proceed confidently in their decision-making. To do otherwise was contrary to basic ideas around what it meant to be a police officer, and not 'knowing' what to do, right or wrong, was seen as inimical to their role, if not downright effete. A lot of discussion around this topic was needed throughout the life of the project.

What kinds of attributes are needed in the leadership to achieve these goals and to avoid these pitfalls? The concepts of transformational and transactional leadership, introduced by Burns (1978) are useful here. According to Judge and Piccolo (2004: 755), "Transformational leaders offer a purpose that transcends short-term goals and focuses on higher order intrinsic needs. Transactional leaders, in contrast, focus on the proper exchange of resources. If transformational leadership results in followers identifying with the needs of the leader, the transactional leader gives followers something they want in exchange for something the leader wants." (p. 755). Whereas transformational leaders are characterised as charismatic and inspirational, transactional leaders are often viewed as more pedestrian, setting up transactions of exchange with those they are leading, clarifying expectations of what is required of them, monitoring performance and anticipating problems.

These two kinds of leadership, however, may not be polar opposites in the way that Burns suggested, but instead appear to be highly correlated. Indeed, both research (Judge and Piccolo 2004: 765) and experience indicates that all successful enterprises require the qualities intrinsic to both styles. The qualities associated with transformational leadership are needed to engender enthusiasm in both the research team and the operational team, but for long-term outcomes, the capacity of the transactional 'manager' (Handy 1993) to ensure that people understand the messages that are being communicated, to give clear and specific instructions and to face up to reality and act when things are not going well are all essential.

These are precisely the qualities required of the experimental field research manager who continually monitors the state of play up and down the hierarchy of both teams and also between the teams. Positive social and professional relationships are essential as has been repeatedly said, but only the field manager can decide whether these exceed the point at which there can be a cross-over of commitment, 
ensuring that a professional distance is retained between the parties, managing the interpretation of the agreed protocol as well as maintaining quality control over the whole enterprise. Only the field manager is in position to see all these relationships and all these activities and to do so engagingly while maintaining a professional distance.

Finally, the field manager must take care of the morale of the research team. The controversies generated by experiments, the length of time they take to complete, the level of cooperation required with the operational agency, the day-by-day grind of generating caseflow - all these can all lead to staffing problems. They need to be carefully monitored and every attempt made to boost flagging spirits with milestone parties, celebrations over victories small and large, heroic efforts recognised and rewarded - whatever is necessary to keep the team focused and optimistic.

\section{Conclusion}

Experiments conform to the laws of Newtonian physics: experimenters sometimes mistakenly believe that they will forever maintain a steady state once put in motion. But they rarely get the chance to do so because they are acted upon by so many contrary forces. And if the research team is not close at hand, they usually come to a full stop. No one has ever suggested that experiments are easy to do, but being aware of the possible pitfalls in advance and of the ingenuity with which experimentalists have solved so many of the most common problems should give heart to those contemplating such a worthwhile enterprise. And it is always vital to remember that all good research, experimental and non-experimental, is painstaking and usually expensive to do right.

There is no doubt that cooperation between researchers and operational partners is essential to this enterprise. The kind of 'coalitions' proposed here as a model for this collaboration may be an intermediate one that will be superseded when the parties have a more mature understanding of each other's position, to be replaced by a full partnership. The point is always to establish and maintain good relations in a common cause by whatever means available.

\section{References}

Berk, R. (2005). Randomized experiments as the bronze standard. Journal of Experimental Criminology, 1 (4), 414-431.

Boruch, R. (1997). Randomized experiments for planning and evaluation. Thousand Oaks, CA: Sage

Burns, JM. (1978). Leadership. New York, Harper \& Row

Braga, A., \& Hinkle, M. (2010). The participation of academics in the criminal justice working group process. In J. Klofas, N. Hipple, \& E. McGarrell (Eds.), The new criminal justice (pp. 114-120). New York: Routledge.

Farrington, D., Ohlin, L., \& Wilson, J. Q. (1986). Understanding and controlling crime. New York: Springer.

Feder, L., Jolin, A., \& Feyderherm, W. (2000). Lessons from two randomized experiments in criminal justice settings. Crime and Delinquency, 46(3), 380-400.

Feder, L., Niolon, P. H., Campbell, J., Wallinder, J., Nelson, R., \& Larrouy, H. (2011). The need for experimental methodology in intimate partner violence: Finding programs that effectively prevent IPV. Violence Against Women, 17(3), 341-360. 
Garner, J., \& Visher, C. (1988). Experiments help shape new policies (Report No. 211). Washington DC: National Institute of Justice Reports.

Gerth, H.H., \& Wright Mills, C. (1948) (1991). From Max Weber: Essays in Sociology. London: Routledge.

Greene, J. (2010). Collaborations between police and research/academic organisations: some prescriptions from the field. In J. Klofas, N. Hipple, \& E. McGarrell (Eds.), The new criminal justice (pp. 121-127). New York: Routledge.

Handy, C. (1993). Understanding organizations (4th ed.). London: Penguin Books.

Hutt, M.D., Walker, B.A., Frankwick, G.L. (1995). 'Hurdle the Cross-Functional Barriers to Strategic Change', Sloan Management Review, pp 22-30.

Judge, T. A., \& Piccolo, R. F. (2004). Transformational and transactional Leadership: A meta-analytic test of their relative validity. Journal of Applied Psychology, 89(5), 755-768.

Mizrahi, T., \& Morrison, J. D. (1993). Community organization and social administration: Advances, trends and emerging principles. Binghampton, NY: Haworth Press.

Petersilia, J. (1989). Implementing randomized experiments: Lessons learned from BJA's intensive supervision program. Evaluation Review, 13(5), 435-458.

Ross, L., \& Blumenthal, M. (1975). Some problems in experimentation in a legal setting. The American Sociologist, 10, 150-155.

Rubin, B. R. (1997). A citizen's guide to politics in america: How the system works and how to work the system'. Armonk NY: M.E. Sharpe.

Shapland, J., Atkinson, A., Dignan, E., et al. (2004). Implementing restorative justice schemes (Crime Reduction Programme): A report on the first year. Home Office Online Report 32/04. London: Home Office.

Shapland, J., Atkinson, A. et al. (2006). Restorative justice in practice: findings from the second phase of the evaluation of three schemes. Findings 274. London: Home Office. http://www.homeoffice.gov.uk/ rds/pubinto1.html.

Shapland, J., Atkinson, A., et al. (2007). Restorative justice: The views of victims and offenders. The third report from the evaluation of three schemes. Ministry of Justice Research Series 3/07. London: Ministry of Justice.

Shapland, J., Atkinson, A., Atkinson, H., Dignan, J., Edwards, L., Hibbert, J., et al. (2008). Does restorative justice affect reconviction? The fourth report from the evaluation of three schemes. Ministry of Justice Research Series 10/08. London: Ministry of Justice.

Sherman, L. W. (1992). The influence of criminology on criminal law: Evaluating arrests for misdemeanor domestic violence. Journal of Criminal Law and Criminology, 83, 1.

Strang, H. (2002). Repair or revenge: Victims and restorative justice. Oxford: Oxford University Press.

Strang, H., \& Braithwaite, J. (eds) (2001), Restorative Justice and Civil Society. Melbourne: Cambridge University Press.

'Student' (WS Gosset) (1931). 'The Lanarkshire milk experiment'. Biometrika, 23(3/4), 398-406.

Weisburd, D. (2000). Randomized experiments in criminal justice policy: Prospects and problems. Crime and Delinquency, 46(2), 181-193.

Weisburd, D. (2005). Hot spot policing experiments and criminal justice research: Lessons from the field. The Annals of the American Academy of Political and Social Science, 599, 220-245.

Weisburd, D., Petrosino, A., \& Mason, G. (1993). Design sensitivity in criminal justice experiments. In M. Tonry (Ed.), Crime and justice: A review of research. Chicago: University of Chicago Press.

Heather Strang is Deputy Director of the Jerry Lee Centre of Experimental Criminology, Institute of Criminology, University of Cambridge. She has been involved in many tests of criminological interventions, mostly notably a series of twelve experiments on the effects of restorative justice in Australia and the United Kingdom. These studies have been conducted at several points in the justice system including courts, probation and prison. She also directs the Centre for Restorative Justice at the Australian National University.

Dr Strang is currently engaged in two experiments with British police forces, one testing alternative strategies in addressing anti-social behaviour and the other a different approach to domestic violence. She has published widely on all these areas of research and is currently reporting on an analysis of a ten year follow-up of victims and offenders who participated in her Australian restorative justice research. 